\title{
Closure to "Discharge Coefficient Analysis for Triangular Sharp-Crested Weirs Using Low-Speed Photographic Technique" by C. Bautista-Capetillo, 0. Robles, H. Júnez-Ferreira, and E. Playán
}

\author{
C. Bautista-Capetillo, A.M.ASCE1; O. Robles2; H. Júnez-Ferreira3; and E. Playán4
}

\begin{abstract}
1Professor, Planeación de Recursos Hidráulicos, Univ. Autónoma de Zacatecas, Ave. Ramón López Velarde 801, 98000 Zacatecas, Mexico (corresponding author). E-mail: baucap@uaz.edu.mx

2Hydraulic Specialist, Planeación de Recursos Hidráulicos, Univ. Autónoma de Zacatecas, Ave. Ramón López Velarde 801, 98000 Zacatecas, Mexico.

3Professor, Planeación de Recursos Hidráulicos, Univ. Autónoma de Zacatecas, Ave. Ramón López Velarde 801, 98000 Zacatecas, Mexico.

4Research Professor, Dept. Suelo y Agua, Estación Experimental de Aula Dei, CSIC, P.O. Box 13034, 50080 Zaragoza, Spain.
\end{abstract}

In the original technical note, an equation was proposed to determine the discharge coefficient (Cd) of triangular sharp-crested weirs. The equation was based on the free-vortex theory. Supporting data were obtained using four fully aerated weirs. An adaptation of the low-speed photographic technique proposed by Salvador et al. (2009) was implemented to obtain the upper and lower nappe profiles.

The discussers A. R. Vatankhah and P. Peysokhan presented an in-depth analysis of our technical note. Additionally, they provided an alternative procedure to estimate $\mathrm{Cd}$, leading to a comparison of the approaches used in both works. The discussers raised several issues that made part of our original research but could not be presented in the technical note due to space limitations. Now that the discussion is open, we are addressing these issues by introducing some of our findings for the particular case of the studied triangular sharp-crested weirs.

As the discussers pointed out, the free-vortex theory applied to sharp-crested weirs includes the analysis of the nonconcentricity of the streamlines, introducing a correction coefficient $(k)$. This consideration addresses the effects of viscosity, capillarity, surface tension and velocity distribution in the approach section, as well as streamline curvature due to the contraction of the liquid vein (Aydin et al. 2011; El-Hady 2011; Bagheri and Heidarpour 2010). The original paper proposed the following expression to determine Cd:

$\mathrm{Cd}=3.750 Z 1[k Z 0+Z 1 \ln (Z 1 Z 1+k Z 0)]$

(1)where $Z 0=0.682[\tan (\theta 2)] 0.044$

(2) $Z 1=0.445[\tan (\theta 2)]-0.098$

(3) $k=1.206[h \tan (\theta 2)]-0.014$

(4) $\mathrm{Z} 0$ and $\mathrm{Z} 1$ correspond to the $\mathrm{Y} / \mathrm{h}$ and $\mathrm{Rb} / \mathrm{h}$ ratios, respectively. Fig. 1 presents the experimental data supporting the development of Eqs. (2) and (3). In this Figure, $Y$ is the flow depth at the maximum elevation section of the lower nappe; $\mathrm{Rb}$ is the radius of the streamline curvature at the lower nappe of the profile in segment $\mathrm{OB}$; and $\mathrm{h}$ is the upstream depth (see Fig. 1 in the original paper). 
For each tested flow, the experimental nonconcentricity of the streamlines $(\mathrm{k})$ was characterized using the low-speed photographic technique proposed by Salvador et al. (2009). The experimental values of $k$ were plotted against the product of $h$ and the vertex angle, expressed as $\tan (\theta / 2)$ (Fig. 2); the regression curve resulted in Eq. (4).

Furthermore, the discussers referred to predictive equations of the discharge coefficient presented by other authors. In Fig. 3 of the original paper, Eq. (1) was compared with some alternative equations to estimate Cd proposed in the literature. These equations and their limitations are presented in Table 1 to facilitate comparison with the equation we proposed.

Finally, the equation proposed by the discussers can be useful to estimate discharge in triangular sharp-crested weirs in the absence of the experimental data used in this research to derive the proposed Eq. (1).

\section{References}

Aydin, I. , Altan-Sakarya, A. B. , and Sisman, C. (2011). "Discharge formula for rectangular sharp-crested weirs." Flow Meas. Instrum. , 22 (2), 144-151. [CrossRef]

Bagheri, S. , and Heidarpour, M. (2010). "Flow over rectangular sharp-crested weirs." Irrig. Sci. , 28 (2 ), 173-179. [CrossRef]

Barr, J. , and Strickland, T. P. (1910). “Experiments upon the flow of water over triangular notches." Engineering , 89 , 435.

Cone, V. M. (1916). "Flow through weir notches with thin edges and full contractions." J. Agric. Res. , 23 , 1051.

El-Hady, R. M. A. (2011). “2D-3D modeling of flow over sharp-crested weirs.” J. Appl. Sci. Res. , 7 (12 ), $2495-2505$.

Greve, F. W. (1932). "Flow of water through circular, parabolic, and triangular vertical-notch weirs." Research Series No. 40, Engineering Bulletin, Purdue Univ., West Lafayette, IN.

King, H. W. (1954). Handbook of hydraulics, McGraw-Hill, New York.

Lenz, A. T. (1943). "Viscosity and surface tension effects on V-notch weir coefficients." Am. Soc. Civ. Eng. Trans. , 108 , 759.

Salvador, R. , Bautista-Capetillo, C. , Burguete, J. , Zapata, N. , and Playán, E. (2009). "A photographic methodology for drop characterization in agricultural sprinklers." Irrig. Sci. , 27 (4 ), 307-317. [CrossRef]

Shen, J. (1981). "Discharge characteristics of triangular-notch thin-plate weirs. Studies of flow of water over weirs and dams." Geological Survey Water-Supply Paper 1617-B, U.S. Dept. of Interior, Washington, DC. 
Fig. 1. $R b / h$ and $Y / h$ versus $\tan (\theta / 2)$ using upper and lower nappe quadratic equations

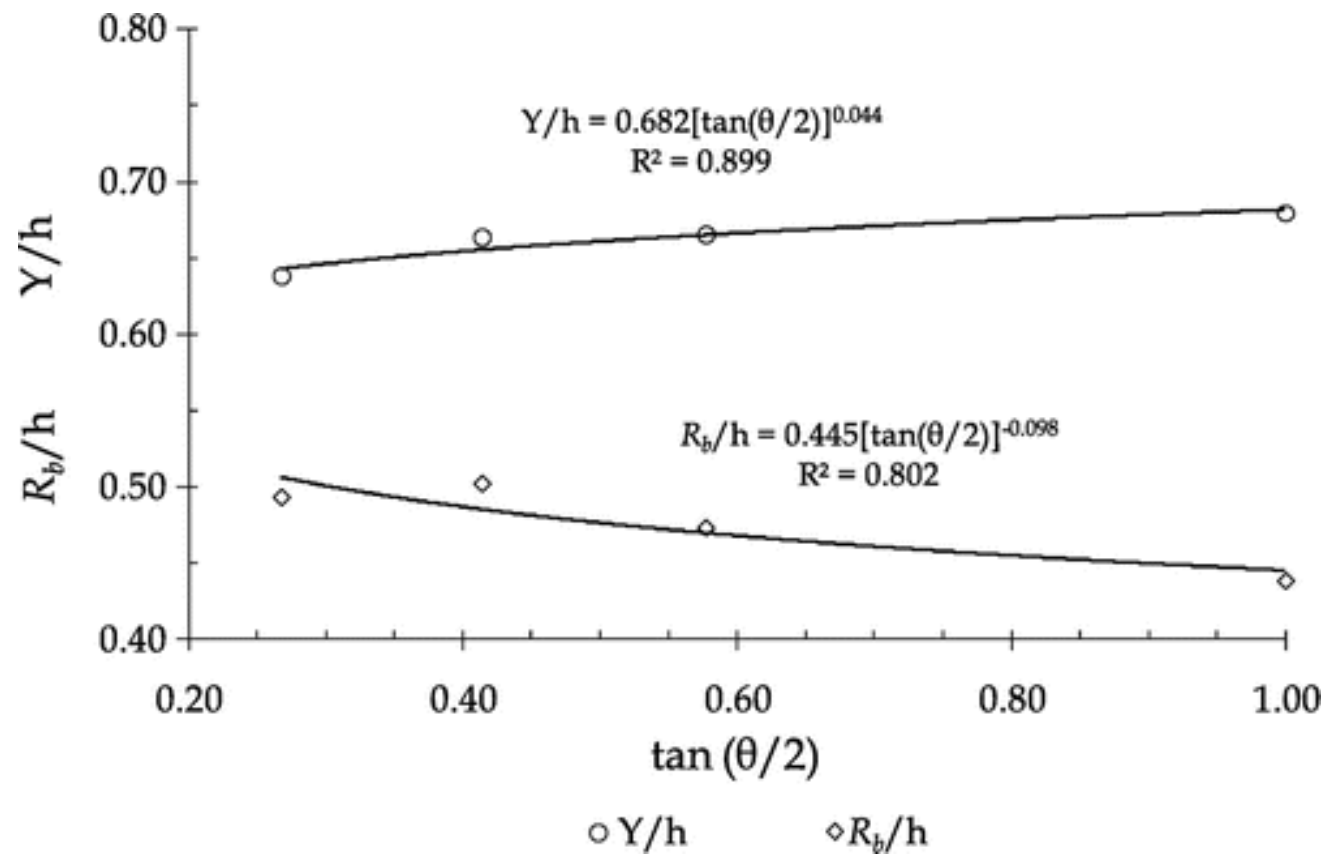


Fig. 2. Variation of $k$ with $h \tan (\theta / 2)$

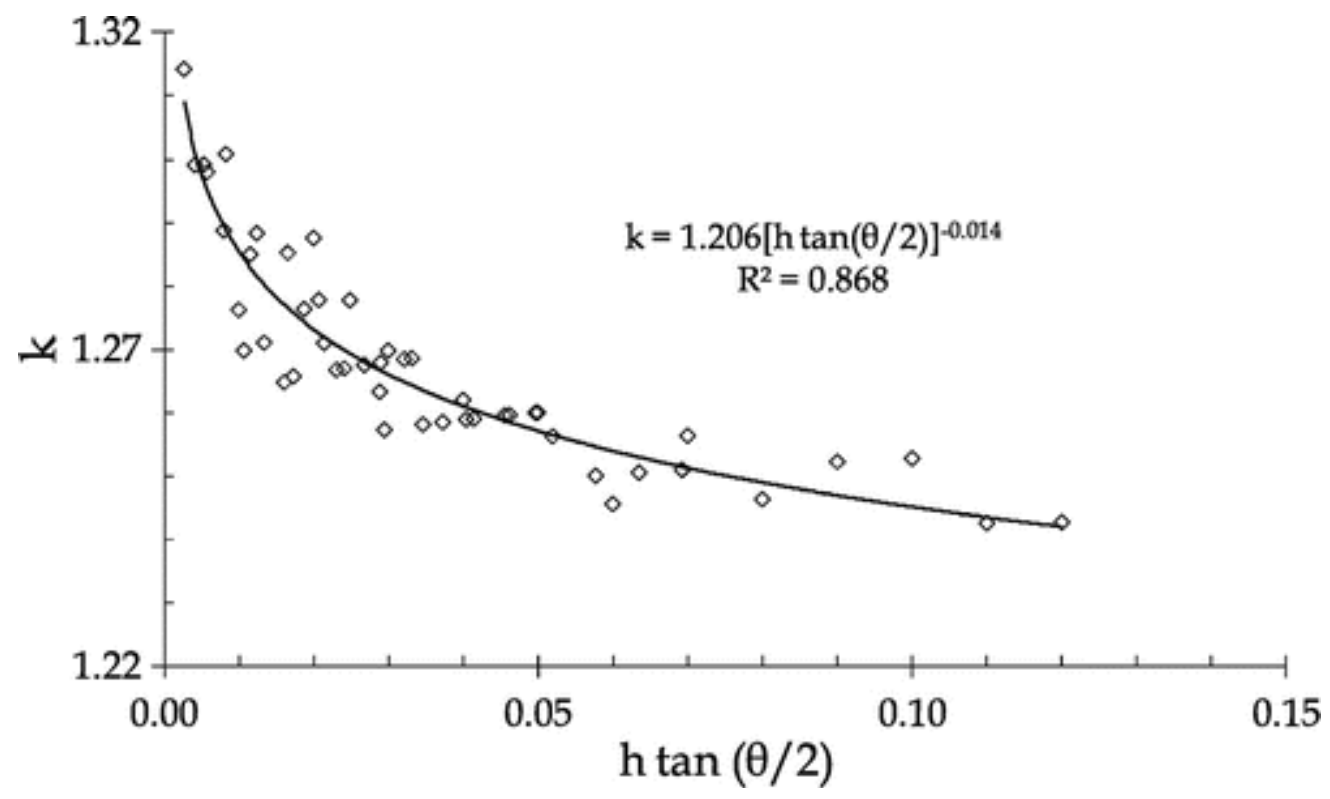


Table 1. Discharge Coefficient for Triangular Sharp-Crested Weir Proposed by Some Authors

\begin{tabular}{|c|c|c|}
\hline Author & Equation & Limitations \\
\hline Barr and Strickland $(\underline{1910}$ & $C d=0.566+0.0157 h \sqrt{ }$ & For $90^{\circ} \mathrm{V}$-notch \\
\hline \multirow[t]{3}{*}{ Cone $(\underline{1916})$} & $C d=0.576 h j+0.00584 S h j$ & For $28-120^{\circ} \mathrm{V}$-notch \\
\hline & & $j=0.0195 S 0.75$ \\
\hline & & $S$ is the slope of the sides of notch \\
\hline Greve (1932) & $C d=0.585[\tan (\theta 2)] 0.004 h 0.03$ & For $20-120^{\circ}$ V-notch \\
\hline Lenz $(\underline{1943})$ & $C d=0.560+N h a$ & For $10-90^{\circ} \mathrm{V}$-notch; $N$ and $a$ are functions of angle vertex weir \\
\hline \multirow[t]{2}{*}{ King (1954) } & $C d=0.595 h 0.01$ & For $60^{\circ} \mathrm{V}$-notch \\
\hline & $C d=0.589 h 0.03$ & For $90^{\circ} \mathrm{V}$-notch \\
\hline
\end{tabular}

Note: $C d=$ discharge coefficient. Equations adapted from Shen (1981). 